\title{
CIS-ATRACURIUM WITH MASSETER MUSCLE SPASM: AN UNANTICIPATED DIFFICULT ENDOTRACHEAL INTUBATION AND TEMPOROMANDIBULAR JOINT DISPLACEMENT: A CASE REPORT
}

\author{
Muhammad Saad Yousuf, Syed Shabbir Ahmed, Khalid Samad \\ Aga Khan University Hospital, Karachi Pakistan
}

\begin{abstract}
Masseter muscle spasm and displacement of temporomandibular joint under anaesthesia could be life threatening if an anaesthesiologist is not prepared. We present a case of 23 years old young lady, who otherwise healthy, having symptoms of abdominal pain and vomiting. Initial baseline workup showed a solitary gallstone and was then planned for urgent laparoscopic cholecystectomy. The challenges faced in the perioperative period were the management of unanticipated masseter muscle spasm and difficult endotracheal intubation after administration of cisatracurium, and temporomandibular joint displacement.
\end{abstract}

Keywords: Cisatracurium, Difficult endotracheal intubation, Masseter muscle spasm, Temporomandibular joint.

\footnotetext{
This is an Open Access article distributed under the terms of the Creative Commons Attribution License (https://creativecommons.org/licenses/by-nc/4.0/), which permits unrestricted use, distribution, and reproduction in any medium, provided the original work is properly cited.
}

\section{INTRODUCTION}

Masseter muscle spasm (MMS) can be defined as severe stiffness of the jaw with marked difficulty to open the mouth manually causing unanticipated difficulty in direct laryngoscopy and endotracheal intubation without temporomandibular joint (TMJ) dysfunction $^{1}$. It is the known complication of drugs such as suxamethonium and volatile agents in patients having muscular disorders or malignant hyperthermia $(\mathrm{MH})$, but rarely it can be encountered following administration of non-depolarizing neuromuscular blocking agents and sedative agents like propofol, fentanyl or remifentanil2-4. So it should not be limited to specific drug groups. Hence, masseter spasm and displacement of TMJ under anaesthesia can be fatal if an anaesthesiologist is unprepared. The patient has provided written consent to publish this case report.

\section{CASE REPORT}

A 23-year-oldyoung lady with no known comorbid, weighing $44 \mathrm{~kg}$ and height of $155 \mathrm{~cm}$, came in emergency department with symptoms of abdominal pain and vomiting for 1 day. Her hemodynamics were; pulse rate of 110 beats/min; blood pressures of 119/71 mmHg; oxygen saturation of $98 \%$ on room air; respiratory rate of $16 / \mathrm{min}$, and temperature of $37^{\circ} \mathrm{C}$. Physical examination showed a soft, non-tender abdomen with audible gut sounds. Her airway assessment showed a Malampatti score-1, adequate mouth opening and normal range of neck and jaw movements. She had a past

Correspondence: Dr Muhammad Saad Yousuf, Department of Anaesthesia, Aga Khan University Hospital, Karachi Pakistan

Received: 26 Apr 2020; revised received: 09 May 2020; accepted: 16 May 2020 surgical history of tongue released at age of 3 years under general anaesthesia. Initial investigations showed a raised total leukocyte counts of $17.5 \times 10^{9} / \mathrm{L}$ while ultrasound showed a cholelithiasis with no evidence to suggest acute cholecystitis.

Patient was shifted to operating room for urgent laparoscopic cholecystectomy. Routine intraoperative monitoring was applied (electrocardiography, noninvasive blood pressure and pulse oximetry) while onewide bore intravenous cannula was inserted. Her base line blood pressure in operating room was 110/70 $\mathrm{mmHg}$, pulserate of 105 beats/min, and oxygen saturation was $98 \%$ on room air. Induction of anaesthesia was done with IV nalbuphine $6 \mathrm{mg}$, propofol $100 \mathrm{mg}$ and cisatracurium $10 \mathrm{mg}$. Bag mask ventilation was done for about 3 minutes with a mixture of oxygen: nitrous oxide (50:50), and isoflurane $1.0 \%$. To proceed for direct laryngoscopy, the mouth opening was suddenly found to have reduced to less than $1 \mathrm{~cm}$ with a locked jaw. An additional $4 \mathrm{mg}$ of cisatrcurium was repeated to rule out the probabilityof inadequate depth of anaesthesia or muscle relaxation and was followed by bag mask ventilation of 3 minutes. The bag mask ventilation was easy and oxygen saturation was maintained to $98 \%$. A second attempt of laryngoscopy was also unsuccessful. A call was given for help. As the teeth were opposed very tightly, so every effort to open the mouth was unsuccessful. The fiber optic bronchoscope was also not immediately available in the operating room due to unanticipated difficult intubation. In subsequent attempts, mouth was eventually opened slightly and with the help of laryngoscope, bougie was inserted to advance the endotracheal tube size of $6.5 \mathrm{~mm}$ 
into the trachea. After the intubation, it was found that the mouth was not closing and the jaw was dislocated. On examination it was found that the TMJ was displaced with the loss of anterior motion of the mandibular condyle (figure). The end tidal carbon dioxide in capnography was $35 \mathrm{mmHg}$ and the temperature was

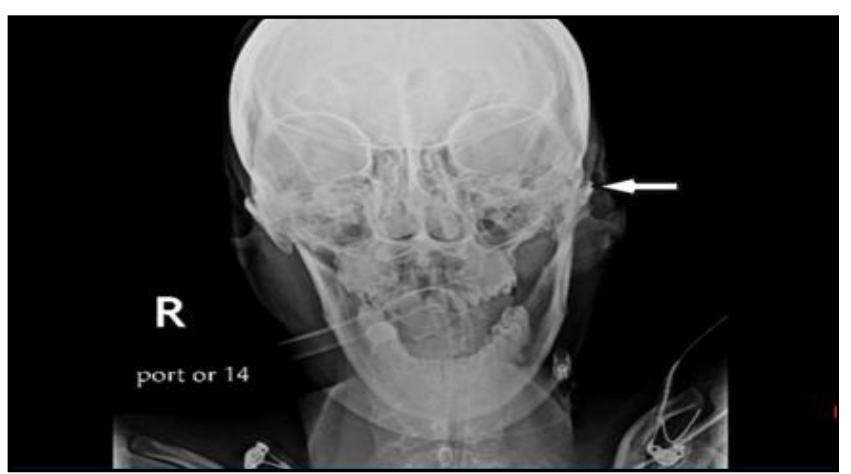

Figure: Panoramic view of Temporomandibular joint: Displacement of left TMJ.

35.6 OC. Anaesthesia was maintained with a mixture of oxygen: air (50:50), and isoflurane 1.0-1.2\%. Surgery was done within a 1 hour and ENT surgical team was called to fix the dislocated jaw with manipulation of mandible. Hemodynamics was maintained throughout surgery. Muscle relaxant was not repeated after induction dose. The patient was weaned gradually, reversed the muscle relaxant effect with neostigmine and extubated within half an hour in the operating room. She was observed in the post anaesthesia care unit for about six hours with adequate mouth opening. She did not report either in herself or her family members about the problems related to MMS with anaesthesia or TMJ disorder. The event was discussed with the patient and family. She was then discharged from hospital on 4th postoperative day.

\section{DISCUSSION}

MMS is considered as severe stiffness of the jaw with marked difficulty to open the mouth manually causing unanticipated diffi-culty in direct laryngoscopy and endotracheal intuba-tion in the absence of TMJ dysfunction ${ }^{1}$. Although it is a rare condition but it can be an early feature of MH. Allen and Rosenberg5, found a $25 \%$ incidence of $\mathrm{MH}$ susceptibility in adult patients with a history of MMS while 59\% incidence was found in pediatric patients having MMS. Approximately half of patients who develop acute MH have had one or two uneventful exposures to triggering agents 6 . Except for the MMS, she did not develop any rigidity in other muscle group and also did not observe any rise in temperature, end-tidal carbon dioxide con- centration and arrhythmias or peaked $\mathrm{T}$ waves associated with hyperkalemia.

Although it is the known complication of drugs such as suxamethonium and volatile agents in patients having any muscular disorders or $\mathrm{MH}$, but rarely it can be encountered following administration of nondepolarizing neuromuscular blocking agents like atracurium $^{7}$, rocuronium, vecuronium or pancuronium ${ }^{8}$, and sedative agents like propofol, fentanyl or remifentanil2-4. Propofol or remifentanil induced muscular rigidity does not occur in completely paralysed patients 9 . So after excluded other possible causes like malignant hyperthermia, inadequate depth of anaesthesia or muscle relaxation, preoperative anxiety, structural abnormalities of the dental and TMJ, and history of neuromuscular disorder, it is more likely that our patient might developed MMS following administration of cisatracurium, which was still not reported in the literature till yet.

However, no definitive literature exists to rule out the tendency of establishing $\mathrm{MH}$ after an event of MMS. Besides MMS, the MH Centre at St James University Hospital did not suggests further investigationsin the absence ofother signs of $\mathrm{MH}$ and the limited duration of exposure 7 . On this basis, we did not investigate her further to rule out the susceptibility of $\mathrm{MH}$ and only observed her in post anaesthesia care unit.

When an anaesthetic is necessary in patients who experienced MMS during a previous anaesthetic but did not evaluate completely for $\mathrm{MH}$ or myopathy, so such patients should be given non-triggering agents for their procedure. We had informed and counselled the patient in detail about her inability to open the mouth soon after the induction of anaesthesia.

Airway management can become hazardous in the presence of MMS. It could lead to fatal situation if an anesthesiologist is not prepared. In this case, the prescribed jaw-thrust maneuver to overcome the locked-jaw and obstruction were also ineffective after the induction of anaesthesia. The equipment like fiber optic bronchoscope was also not available immediately in the operating room due to unanticipated difficult intubation. After multiple attempts, mouth was eventually opened slightly and with the help of laryngoscope, bougie was inserted to advance the endotracheal tube size of $6.5 \mathrm{~mm}$ into the trachea. After the intubation, it was found that the mouth was not closing and the jaw was dislocated as illustrated in figure. So, with proper airway management, MMS cannot lead to hazardous situation. 


\section{CONCLUSION}

MMS can lead to the difficulty in mouth opening and TMJ dislocation following induction of anaesthesia. It should not be limited to specific drug groups. One of the major goals is to maintain adequate oxygenation and the immediate availability of fiberoptic bronchoscope. A standardized approach to these patients is important so that the hazardous conditions can be overcome effectively.

\section{CONFLICT OF INTEREST}

This study has no conflict of interest to be declared by any author.

\section{REFERENCES}

1. Woodward KT. Patient 37. In: Duke JC, editor. Anesthetic Pearls. Philadelphia: Hanley and Belfus Inc.; 2003. p.151-4.

2. Raut MS, Maheshwari A, Jyoti A, Joshi S. Jaws of steel after rocuronium. Indian J Anaesth 2016; 60(2): 141-2.
3. Nakada J, Nishira M, Hosoda R, Funaki K. Priming with rocuronium or vecuronium prevents remifentanil mediated muscle rigidity and difficult ventilation. J Anesth 2009; 23(3): 323-8.

4. Saeidi M, Alikhani R, Hormati A, Sabouri SM, Aminnejad R. Propofol-induced masseter muscle spasm in a woman with a major depressive disorder. Anesth Pain Med 2018; 8(3): e78748-52.

5. Allen GC, Rosenberg H. Malignant hyperthermia susceptibility in adult patients with masseter muscle rigidity. Can J Anaesth 1990; 37(1): 31-5.

6. Larach MG, Gronert GA, Allen GC, Brandom BW, Lehman EB. Clinical presentation, treatment, and complications of malignant hyperthermia in North America from 1987 to 2006. Anesth Analg 2010; 110(2): 498-7.

7. Reddy K, Bromley L. Masseter muscle spasm following atracurium. Anaesth 2004; 59(5): 513-16.

8. Albrecht A, Wedel DJ, Gronert GA. Masseter muscle rigidity and nondepolarizing neuromuscular blocking agents. Mayo Clin Proc. 1997; 72(4): 329-32.

9. Islander G, Vinge E. Severe neuroexcitatory symptoms after anaesthesia - with focus on propofol anaesthesia. Acta Anaesthesiol Scand 2000; 44(2): 144-49. 